\title{
Incorporating risk mapping at multiple spatial scales into eradication management plans
}

\author{
Haylee Kaplan • Adriaan van Niekerk • \\ Johannes J. Le Roux • David M. Richardson • \\ John R. U. Wilson
}

Received: 23 November 2012/ Accepted: 16 September 2013/Published online: 19 December 2013

(C) Springer Science+Business Media Dordrecht 2013

\begin{abstract}
The success of pro-active management of invasive plants depends on the ability to rapidly detect invasive populations and individuals. However, the factors important for detection depend on the spatial scale examined. We propose a protocol for developing risk maps at national, landscape, and local scales to improve detection rates of invasive plant species. We test this approach in the context of developing an eradication plan for the invasive tree Acacia stricta in South Africa. At a national scale we used bioclimatic models coupled with the most likely sites of introduction (i.e. forestry nursery plantations) to identify areas
\end{abstract}

Electronic supplementary material The online version of this article (doi:10.1007/s10530-013-0611-z) contains supplementary material, which is available to authorized users.

H. Kaplan · J. J. Le Roux · D. M. Richardson ·

J. R. U. Wilson $(\bowtie)$

Department of Botany and Zoology, Centre for Invasion

Biology, Stellenbosch University, Matieland 7602,

South Africa

e-mail: john.wilson2@gmail.com;

invasivespecies@sanbi.org.za

A. van Niekerk

Department of Geography and Environmental Studies,

Centre for Geographical Analysis, Stellenbosch

University, Matieland 7602, South Africa

\section{J. R. U. Wilson}

Invasive Species Programme, South African National Biodiversity Institute, Kirstenbosch Research Centre, Claremont 7735, South Africa where national-scale surveillance should be focussed. At the landscape and local scales we correlated the presence of A. stricta populations to various attributes. Regional populations were found in forestry plantations only, and mostly on highly used graded roads along which seeds are spread by road maintenance vehicles. Locally, previously recorded plant localities accurately predicted individuals in subsequent surveys. Using these variables, we produced a map of high-risk areas that facilitated targeted searcheswhich reduced the required search effort by ca. $83 \%$ - and developed recommendations for site-specific surveying. With the high visibility of plants, and relatively small seed banks, long-term annual clearing should achieve eradication. We propose that such multi-scale risk mapping is valuable for prioritising management and surveillance efforts, though caution that the approach is correlative and so it does not represent all the sites that can be invaded.

Keywords Biological invasions - Early detection - Eradication - Invasive plant · Risk mapping $\cdot$ Surveillance $\cdot$ Tree invasions

\section{Introduction}

Management of invasive species is most effective when invasions are detected early and comprehensive control measures are implemented rapidly enough to prevent widespread impacts from accruing 
(Simberloff 2003b). In this context, eradication is often a desirable goal (Myers et al. 2000). However, because attempting eradication is usually expensive, with a high probability of failure (Gardener et al. 2010; Panetta 2009; Simberloff 2003a), thorough evaluation of the feasibility of eradication is crucial. Eradication of plant species is usually only considered feasible for species with small range sizes (Rejmánek and Pitcairn 2002). However, the success of eradication is not only influenced by range size, but also on the ability to find all propagules. As a species' invasive range increases, there is a greater need to accurately delimit the extent of the invasion (i.e. number and size of populations) to determine eradication feasibility (Moore et al. 2011; Panetta and Lawes 2005). Quantifying the risk of postintroduction spread via particular vectors, along different pathways and into given habitats and ecosystems has become a strong focus of research in invasion science in the last two decades (e. g. Pyšek and Richardson 2010).

The costs and effort required to search for a species over a large potential range are often prohibitively high. Furthermore, there is a high probability of missing invasive populations using random searching (Cacho et al. 2006). Invasion delimitation therefore requires systematic search protocols that enable rapid delimitation of all invasive stands and sufficient surveillance to detect any new populations that result from spread. Consequently, identifying areas where search efforts should be focussed, based on probability of invasion success in those areas, can reduce costs and effort associated with delimiting the extent of an invasion.

Habitat suitability predictions have been used to identify vulnerable areas for invasions and predict spread pathways of invasive plant species in order to improve search and management strategies (Butcher and Kelly 2011; Giorgis et al. 2011; Peltzer et al. 2008; Vanderhoof et al. 2009). If eradication of plant species is to be attempted, early detection of new populations is essential. However, the probability of detecting new populations before they attain reproductive maturity is often low (Kery and Gregg 2003). In addition, species with long-lived seed banks may be present at a site but remain undetected until germination is stimulated (Cacho et al. 2007). Having a better idea of where to conduct intensive searches for a species could reduce the overall search effort and minimise the risk of undetected populations. Highlighting areas with high suitability or risk of invasion by a species will thus improve the efficiency of searching and enable early detection of populations before they increase in size and extent.

Understanding the pathways and vectors of dispersal for a species is an essential step in the development of a search protocol (Pyšek and Richardson 2010). However, different processes might act at different spatial scales. At a broad scale, it is mainly the pathways of introduction and potential agents of rare long distance dispersal (e.g. riparian dispersal) that need to be considered when trying to locate populations of a species. At local-scale seed dispersal vectors may prove more important in determining where to look for plants at a particular site. It is therefore important to understand the mechanisms driving both natural and anthropogenic dispersal at different scales in order to accurately detect and delimit an invasion.

The aim of this study is to develop such a multi-scale assessment and apply it to a case-study of an on-going eradication attempt. Here we propose a framework for improving the detection of naturalised plant populations for accurate delimitation of the species' extent (Fig. 1). Using Acacia stricta as a case study, we identify steps to rapidly and cost-effectively detect populations, thereby allowing an estimate of the feasibility of eradication. Using a risk mapping approach that includes bioclimatic and habitat suitability modelling, we apply predictions of potential range and spread pathways to target searches and awareness to areas of high risk of invasion at national, landscape and local scales in order to maximise detection of all invasive populations. We also consider the value of passive surveillance (i.e. reports from local land owners; Cacho et al. 2010) in locating and monitoring A. stricta populations. In addition, we identify reproductive traits (e.g. seed production, seed bank size) and dispersal mechanisms (i.e. vectors of seed spread) that may influence the feasibility of eradication.

\section{Study system}

Australian acacias have been proposed as a model system for studying biological invasions (Richardson et al. 2011). Given their substantial impacts and the difficulties in controlling extensive seed-banks, control of new acacia invasions should be proactive. To date, no Australian acacia species has been formally recorded as eradicated as part of any weed control 
Fig. 1 Important steps in delimiting an invasion for the assessment of management feasibility

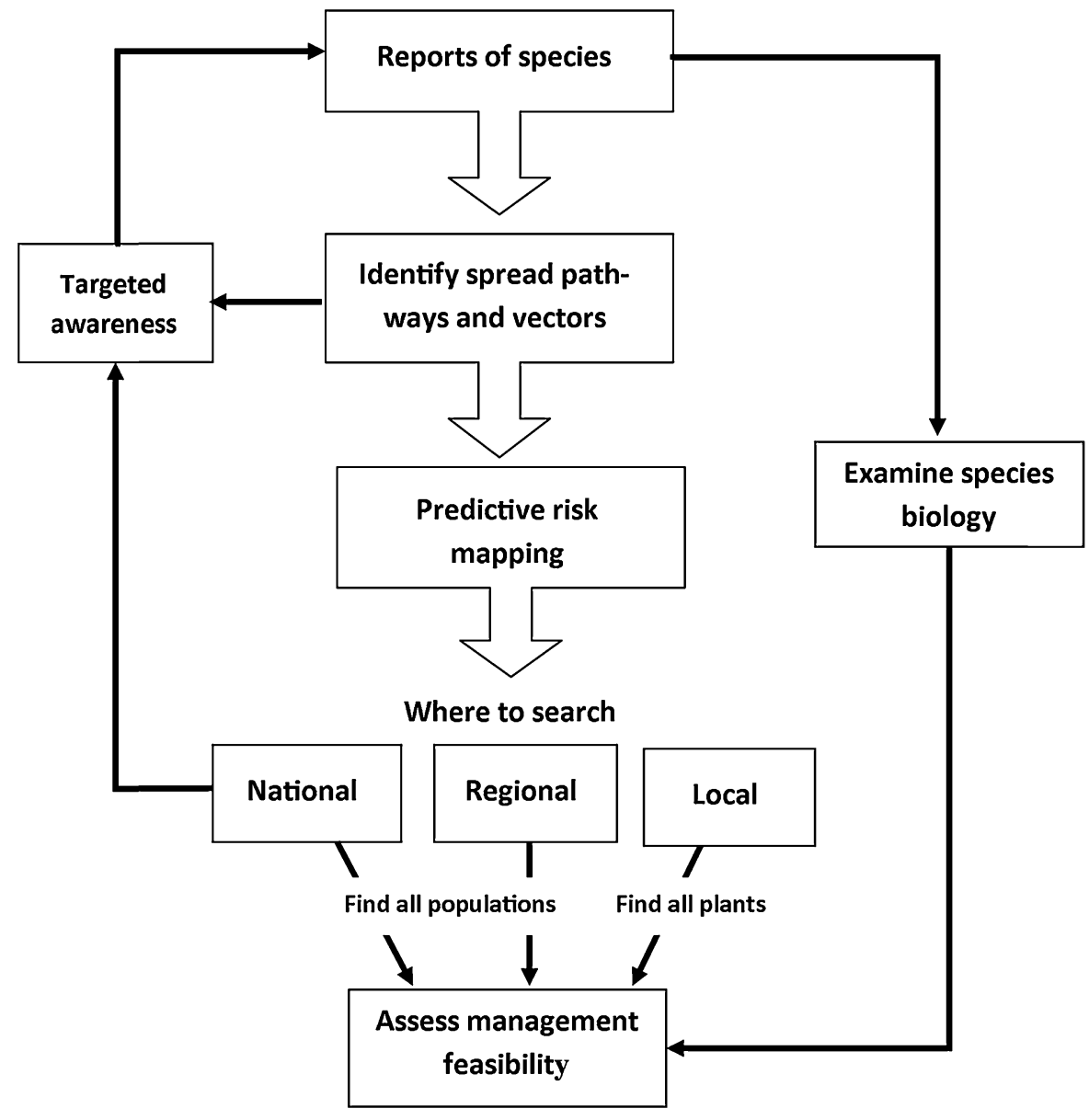

programme (Wilson et al. 2011). In South Africa there are several widespread invasive Australian acacia species that have had large-scale damaging impacts on local ecosystem services and biodiversity (Gaertner et al. 2009; Le Maitre et al. 2011). Besides these widespread invaders, there are a few Australian acacia species that have not yet become widespread, most likely because they were not highly utilized and thus not widely disseminated, or because of relatively short residence times. These species still exist in isolated populations, some of which may be suitable candidates for eradication (van Wilgen et al. 2011). Of these species, three are currently being targeted for eradication by the South Africa National Biodiversity Institute's Invasive Species Programme (Wilson et al. 2013). The first two, A. paradoxa and A. implexa are known to occur at only a few sites and eradication of these two species is considered feasible (Kaplan et al. 2012; Zenni et al. 2009). The third species, A. stricta, was reported from several sites (SAPIA; Henderson determine whether eradication is feasible.

Acacia stricta (Andrews) Willd. is a small tree native to south-eastern Australia. It is not known to be invasive elsewhere in the world, although it is recorded as naturalised in New Zealand (Richardson et al. 2011). Unlike most Australian acacia species that have been introduced to South Africa, there are no records of introduction or planting of $A$. stricta (Poynton 2009). Since 2004 it has been reported by local foresters and conservation managers as a problematic invader in the Knysna area of the Western Cape Province, South Africa.

Similar to the initial stages of many other invaders, A. stricta is currently found mostly in highly disturbed areas, particularly along roads. Roads have been shown to be major conduits for the spread of invasive species due to high levels of disturbance that promotes colonisation (Gelbard and Belnap 2003; Harrison et al. 2002; Spooner et al. 2004) and greater dispersal
1998) and as such requires further investigation to 
opportunities for seeds when road maintenance vehicles move soil (Ferguson et al. 2003; Mortensen et al. 2009; Taylor et al. 2012). The disjunct distribution of A. stricta and uncertainty of the overall distribution of the species in South Africa, together with good knowledge of Australian acacia invasions in general (Richardson et al. 2011), make this a suitable system to explore processes in determining management feasibility within the proposed framework.

\section{Methods}

National-scale assessment of likely sites of invasion

To identify areas where there is a high-risk of introduction and invasion, we considered two primary factors: climatic suitability and potential introduction pathways.

\section{Climatic suitability}

We modelled the potential distribution of Acacia stricta in South Africa (the extent of bioclimatically suitable conditions) using MAXENT 3.3.2 (Phillips et al. 2006). Presence data was compiled from 762 native range records of $A$. stricta from the Australian Virtual Herbarium (chah.gov.au/avh/; accessed 14 July 2010). The background for the model was drawn from A. stricta's range in eastern Australia. The model was trained using all presence data. Duplicate records within each 5-min grid cell were deleted. Our modelling protocol followed that described by Thompson et al. (2011).

The climate variables used were the eight least inter-correlated bioclimatic variables from the WORLDCLIM dataset (www.worldclim.org, Hijmans et al. 2005): mean annual temperature, mean diurnal range in temperature, isothermality, temperature seasonality, mean annual precipitation, precipitation of the driest month, precipitation seasonality, and precipitation of the warmest quarter (Loiselle et al. 2008).

Model error, based on the predicted suitability, was estimated using a 10-fold cross-validation. The ability of the model to correctly predict actual occurrences was assessed using the average test area under curve (AUC).

\section{Introduction pathways}

Acacia stricta is not used for forestry purposes in Australia or anywhere else in the world. However, although there are no historical records of A. stricta being cultivated or used for forestry in South Africa (Glen 2002; Poynton 2009), both our field observations and opinions of local experts suggest that it was either intentionally or unintentionally (as a result of taxonomic misidentification) introduced along with other Acacia species by the forestry industry and was likely kept initially in forestry nurseries. We therefore overlaid areas of bioclimatically suitable conditions onto all plantations in the country in order to identify plantations within climatically suitable areas (Fig. 2a) that would be considered high risk for A. stricta introduction. These areas are being targeted for awareness campaigns (including the distribution of information leaflets; Supplementary Material Appen$\operatorname{dix}$ A).

Delimiting invasions at a landscape scale

To detect populations at a landscape scale, we first consulted land-owners, forestry plantation managers, and regional conservation managers in the Knysna area (to date the only known area where A. stricta is invading in South Africa). Eight localities were identified and used as a starting point for surveying. The localities occurred within a total area of approximately $1,900 \mathrm{~km}^{2}$ in the Knysna and Wilderness areas of the Garden Route National Park (Fig. 2b).

\section{Vehicular surveys}

In 2010, roads in the affected area were searched during the flowering period of A. stricta (AugustSeptember) when plants were most likely to be visible. A total of $\sim 523$ unique $\mathrm{km}$ of roads were searched within the study area (approximately $20 \%$ of the total road matrix). Searching was done from a vehicle driving at an average speed of $\sim 20 \mathrm{~km} / \mathrm{h}$ with a driver and one observer. The study area has an extensive road network, and with no prior knowledge of where to search and insufficient time to survey every kilometre of road, vehicle surveys were directed based on accessibility and proximity to the localities identified as containing A. stricta. 


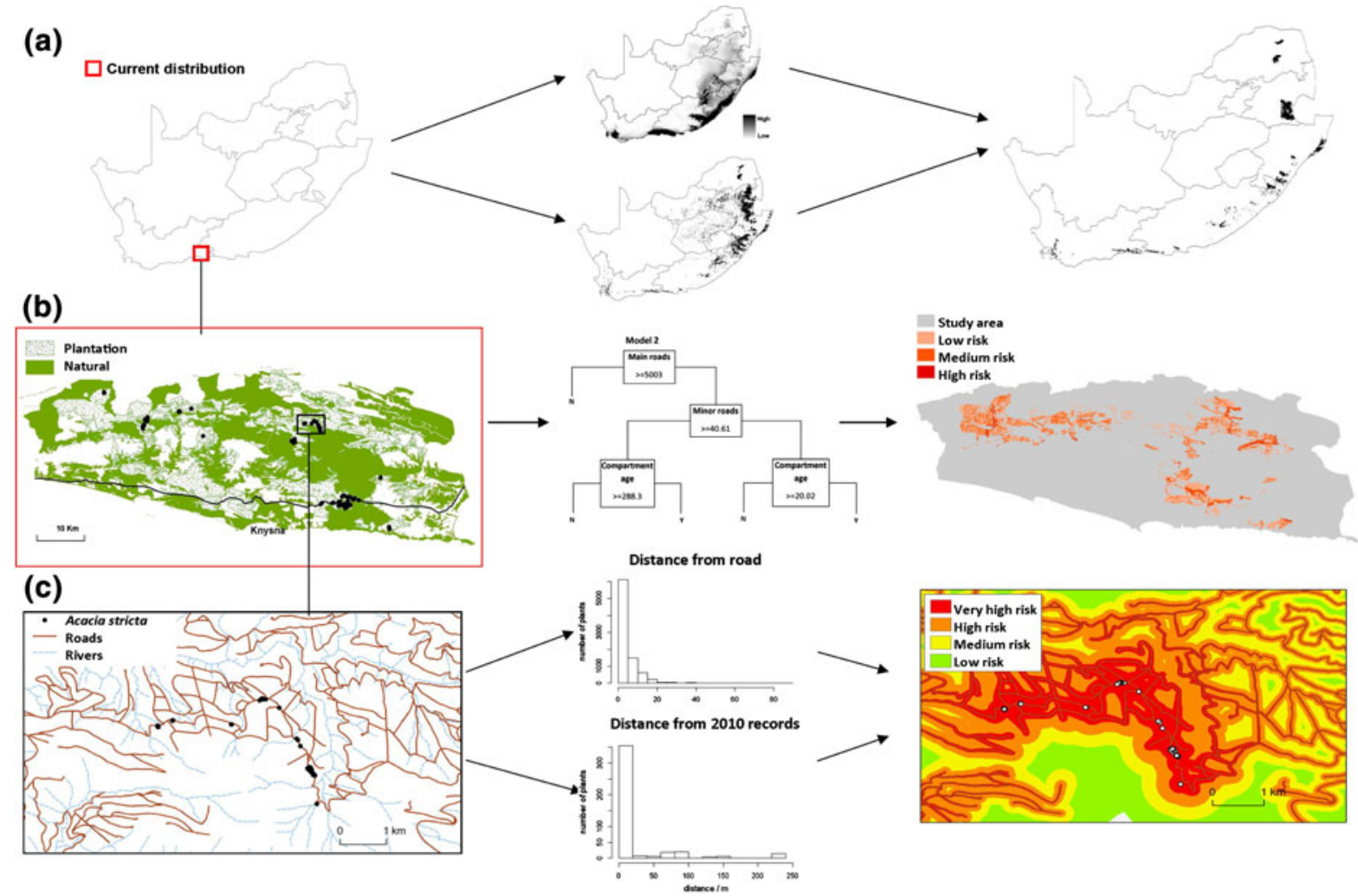

Fig. 2 Risk maps for Acacia stricta were produced to improve surveillance at a variety of spatial scales. At a national scale (a), a climate model and a map of forestry plantations were overlaid to determine where an awareness campaign should be directed; at a landscape scale (b), correlates of the known invaded distribution (distance to particular road type and compartment

\section{Risk mapping (landscape level)}

To more effectively direct search efforts for A. stricta surveillance at a landscape scale, we created a risk map. We based the model on presence data collected during surveys in 2010 and a set of 1,000 pseudo absence data from within the study area, randomly generated using ArcGIS 10.0. A second set of 1,000 absence points restricted to within $50 \mathrm{~m}$ of roadsides was generated to check for any bias towards roadsides that may have resulted from the pseudo-absence point selection. Not surprisingly, as all populations occurred in plantations (mostly pine), initial models returned land use (forestry) as the most significant variable (despite $40 \%$ of the surveyed road lengths being nonplantations, see results). Consequently, in later models the area considered was restricted to plantations (roughly $23 \%$ of the study site). To account for how age) were used to determine similar areas that should be prioritised for future survey; and at a local scale (c), the position of plants found, in relation to distance to roads and locations of plants from the previous year, was used to inform criteria for which areas should be searched in detail (i.e. on foot)

different levels of spatial autocorrelation could affect the model results, presence and absence data were also sub-sampled using grid and random sampling at three spatial resolutions (Table 1).

To identify factors that could influence the spread of $A$. stricta we selected six abiotic and anthropogenic variables as possible predictors of A. stricta occurrence (Table 2). Variables were extracted at each sampled presence or absence point from various land cover and topographic map layers $(10 \mathrm{~m} \times 10 \mathrm{~m}$ resolution) in a geographical information system (GIS). Anthropogenic variables included were postfire vegetation age (germination of Australian acacia seeds is known to be stimulated by fire for many species; Richardson and Kluge 2008), distance to roads [as roads can act as conduits for invasions (Gelbard and Belnap 2003; Mortensen et al. 2009), and disturbance from road maintenance can increase 
Table 1 Point selection and spatial resolution of models used to predict the occurrence of Acacia stricta

\begin{tabular}{|c|c|c|c|c|}
\hline & Model 1 & Model 2 & Model 3 & Model 4 \\
\hline $\begin{array}{l}\text { Spatial } \\
\text { resolution }\end{array}$ & $10 \mathrm{~m} \times 10 \mathrm{~m}$ & $500 \mathrm{~m} \times 500 \mathrm{~m}$ & $\begin{array}{l}10 \mathrm{~m} \times 10 \mathrm{~m} \text {, but only one presence } \\
\text { point used per population (selected at } \\
\text { random) }\end{array}$ & $\begin{array}{l}500 \mathrm{~m} \times 500 \mathrm{~m} \text { Absence } \\
\text { points restricted to }<50 \mathrm{~m} \\
\text { from roadsides }\end{array}$ \\
\hline $\begin{array}{l}\text { Sample } \\
\text { size }\end{array}$ & $\begin{array}{l}\text { 2,000 data points } \\
\text { (1,000 presence/ } \\
1,000 \text { absence })\end{array}$ & $\begin{array}{l}90 \text { data points ( } 45 \\
\text { presence/45 } \\
\text { absence) }\end{array}$ & $\begin{array}{l}\text { 1,009 data points ( } 9 \text { presence/1,000 } \\
\text { absence) }\end{array}$ & $\begin{array}{l}90 \text { data points (45 presence } / 45 \\
\text { absence) }\end{array}$ \\
\hline
\end{tabular}

The study area was as defined by Fig. $2 b$, based on selection of entire tertiary catchments (from sea level to top of catchment) where A. stricta was present. Absence points were restricted to those cells where no plants were present

Table 2 Summary of variables used in classification tree models predicting the occurrence of Acacia stricta

\begin{tabular}{|c|c|c|}
\hline Variable & Description & Values \\
\hline $\begin{array}{l}\text { Post-fire } \\
\text { vegetation } \\
\text { age }\end{array}$ & $\begin{array}{l}\text { Number of years since last } \\
\text { fire (bounded numeric) }\end{array}$ & $\begin{array}{l}\text { Years from } 0 \text { to } \\
\text { a maximum of } \\
>100\end{array}$ \\
\hline Elevation & $\begin{array}{l}\text { Metres above mean sea } \\
\text { level }\end{array}$ & 0 to $1,184 \mathrm{~m}$ \\
\hline Rainfall & Mean annual rainfall & $\begin{array}{l}679 \text { to } \\
1,061.2 \mathrm{~mm}\end{array}$ \\
\hline $\begin{array}{l}\text { Compartment } \\
\text { age }\end{array}$ & $\begin{array}{l}\text { No. of years since planting } \\
\text { or clear felling of } \\
\text { plantation compartments }\end{array}$ & 0 to 89 years \\
\hline $\begin{array}{c}\text { Distance from } \\
\text { minor roads }\end{array}$ & $\begin{array}{l}\text { Gradable roads, hiking } \\
\text { trails, plantation access } \\
\text { roads }\end{array}$ & 0 to $1,462 \mathrm{~m}$ \\
\hline $\begin{array}{l}\text { Distance from } \\
\text { main roads }\end{array}$ & $\begin{array}{l}\text { National routes, main } \\
\text { roads, secondary roads, } \\
\text { urban streets }\end{array}$ & 0 to $9,588 \mathrm{~m}$ \\
\hline
\end{tabular}

recruitment of Acacia species (Spooner et al. 2004)], and compartment age (disturbance and vehicle movement during plantation activity might aid in the dispersal and recruitment of $A$. stricta). Elevation and rainfall were highly variable across the study area and were included in the model to test whether these abiotic conditions influence $A$. stricta occurrence.

To test whether these variables influenced the observed distribution of A. stricta, we used classification trees (to minimise the influence of correlation between variables). Trees were drawn using recursive partitioning (package rpart) in R 2.11.0 (R Development Core Team 2010) for each of the three subsets of data. Trees were pruned to minimise the crossvalidated prediction error estimates. Misclassification errors were calculated for each tree using a test dataset of 256 presence and pseudo absence points sampled at a $100 \mathrm{~m}$ resolution from the study area. Prediction accuracy was estimated based on the AUC value of each model. The best tree was projected back onto the study area in ArcGIS 10.0 to produce a probability map of A. stricta occurrence and highlight areas suitable for future spread and where search effort should be directed to detect invasive populations.

Local-scale detectability

To improve detectability at a finer scale we needed to know where to look for individual plants. To do this we conducted detailed search-and-destroy site surveys and mapped local-scale distribution patterns of the populations over two consecutive seasons (2010, 2011). Distributions were then assessed for possible dispersal pathways and vectors. The data were also used to assess whether the location of plants in year 1 could predict the location of plants in year 2 (given that seed production was prevented in year 1 this essentially gives an idea of the site fidelity regarding recruitment from seed-banks).

Every invaded site identified during the vehicle survey was searched on foot. Two surveyors walked survey lines parallel to the road $\sim 10 \mathrm{~m}$ apart, such that at least $30 \mathrm{~m}$ each side of the road was searched. The location of each plant found and its distance to the road edge (to nearest $0.5 \mathrm{~m}$ ) were recorded. Hiking trails that intersected roadside infestations were also surveyed. Searches were discontinued at a site when no plants were found for at least $250 \mathrm{~m}$ along the road in both directions.

Local-scale distribution and spread patterns were then assessed in relation to potential spread pathways. Acacia stricta seeds might be dispersed in soil movement along roads or be washed down watercourses that intersect the invaded sites, so roads and rivers were considered as potential vectors for A. stricta. We compared distances of plants to either potential vector as well as comparing 
locations of plants between surveys to estimate the amount of local spread that could occur in one year. Based on these observed associations we highlighted risk zones at a local scale where plants were most likely to be found and where more intensive searching is required away from the road edge.

\section{Management planning}

To assess the feasibility of eradicating A. stricta populations we investigated features of the species' reproductive biology and its response to management treatments used during the initial clearing. This provided an estimate of the costs and effort that would be required to eradicate the species.

\section{Risk assessment}

To date, Acacia stricta has not been assessed as an invasive species anywhere in the world. To collate relevant literature and to determine whether, as for most Australian acacias (Wilson et al. 2011), A. stricta would have failed a pre-border assessment we conducted an Australian Weed Risk Assessment (Pheloung et al. 1999), using the guidelines for applying the assessment scheme to areas outside Australia (Gordon et al. 2010).

\section{Reproductive output}

Plant height and the presence of reproductive features (i.e. flowers or seedpods) were recorded for all plants found during the survey. Size at reproduction was estimated from the complete data set collected during the flowering period in 2010 using a generalised linear model with binomial errors (with presence of reproductive structures as the response variable). To estimate how reproductive output scales with plant size, we measured plant height and number of flower buds present on plants for 70 individuals at one site. Flower bud counts were used as a proxy for seed production per plant.

\section{Seed banks and seed viability}

To get a preliminary estimate of seed bank size, three $0.5 \times 0.5 \mathrm{~m}$ soil samples dug to a depth of $\sim 10 \mathrm{~cm}$ were taken from beneath single large plants (5-6 m tall). Samples were sieved through a graduated sieve stack and seeds counted. As road grading (resurfacing and digging of drainage ditches on gravel roads) is thought to be the primary dispersal agent of A. stricta seeds, we also sampled soil that had accumulated on the blade of a road grader immediately after it had dug a drainage ditch into a roadside patch of A. stricta (Supplementary Material Appendix B). This was to determine whether seeds were able to be transported along roads during road grading. To provide an estimate of how far off the road seeds were deposited, soil-cores $(8 \mathrm{~cm}$ diameter $\times 10 \mathrm{~cm}$ depth) were taken along transects that intersected a newly graded plantation road. The road had no large plants but a large number of seedlings were observed on the road which indicates that seeds had probably been deposited during road maintenance. A total of 11 transects spaced $10 \mathrm{~m}$ apart were positioned perpendicular to the road and extending $6 \mathrm{~m}$ either side of the road. Core samples were dug at $2 \mathrm{~m}$ intervals along each transect $(\mathrm{N}=77)$.

Seeds collected from soil sampled beneath canopies were tested for viability using a standard tetrazolium test (Peters 2005). A sample of 200 seeds $(50 \times 4$ replicates) was first scarified using sulphuric acid and then stained using a $1 \% 3$, 5-triphenyl tetrazolium chloride solution ( $\mathrm{pH} 6.7$ ) for $72 \mathrm{~h}$. Seed coats were removed and viable seeds (indicated by even staining) counted.

\section{Regrowth from the seed bank}

Once plants had been recorded and measured, depending on size, they were either pulled up by the roots or cut at the base and sprayed with $3 \%$ glyphosate $360 \mathrm{~g} /$ $1 \mathrm{SL}$ herbicide. The initial survey and clearing in 2010 took 38 field days (or 114 person days) to complete. The study area was resurveyed in September 2011 both to remove seedlings that had germinated and to determine whether the survey and clearing of $A$. stricta in 2010 was effective in finding populations and reducing population numbers. The same destructive sampling method was used to survey all previously recorded sites, and incidences of resprouting were recorded. The follow-up survey took approx. 17 field days (or 51 person days) to complete.

\section{Results}

National-scale assessment of likely sites of invasion

The bioclimatic model provided a good fit to A. stricta's distribution in its native range (AUC $=0.971 \pm 0.004$ 
SD). Projection of the model to South Africa (Fig. 2a) predicted high climatic suitability over $\sim 15 \%$ of the country. The bioclimatic variables that contributed most to the model were precipitation of the driest month and annual mean temperature (relative contributions of 49.2 and $18.7 \%$ respectively). Using these bioclimatic suitability predictions and the observed association of A. stricta with plantation areas, we highlighted all plantations within climatically suitable areas in the country where search efforts should be expanded (Fig. 2a). These areas amount to approximately 685,500 ha or about $36 \%$ of the total forestry land in the country.

Delimiting invasions at a landscape scale

The survey of the study area in 2010 found 19,843 A. stricta plants at eight localities, with a total invaded area of $\sim 110$ ha (estimated using minimum convex polygons; Fig. 2b). All eight localities had been reported to us by local plantation and conservation managers, i.e. without prior information, we found no additional populations during driving surveys. All populations occurred on forestry plantations with no spread as yet into adjacent fynbos or native forest. Approximately $60 \%$ of the initial vehicle search was done in plantations, with 25,10 and $5 \%$ of the total searched area comprising natural habitats, farmland and urban areas respectively.

\section{Landscape-scale risk map}

Classification trees for models 1 and 2 provided good predictions of A. stricta occurrence at a landscape scale (AUC $=0.792$ and 0.784 respectively). Model 3 (which included only 9 presence points) did not identify any variables that discriminated A. stricta occurrence. The misclassification error of model 1 was 32.8 and $25.4 \%$ for model 2 . Based on the lower misclassification error and the simpler rules defined by model 2 , we selected this model as most suitable for predicting A. stricta occurrence. The model predicts A. stricta occurrence based on distance to roads and age of plantation compartments. The results were similar for model 4 (where data were restricted to roadsides only, see Supplementary Material Appendix C) but there was a lower prediction accuracy $(\mathrm{AUC}=0.679$ ).
The resulting risk map (Fig. 2b) predicted that $\sim 579 \mathrm{~km}$ of roads within the study area are at high risk of invasion by $A$. stricta and should be the focus of search efforts. This is $17 \%$ of the total $\sim 3,425 \mathrm{~km}$ road network in the study area and would involve travelling 1,281 km of roads (Supplementary Material Appendix D). Unfortunately only $30 \%$ of the highrisk areas were surveyed in 2010 and 2011 . However, the model correctly predicted the location of a new population found in the 2011 survey as a high-risk area (this population was outside the area covered by the vehicle surveys used to develop the risk maps).

Local-scale detectability

The majority (99\%) of plants recorded occurred within $20 \mathrm{~m}$ of roads (Fig. 2c). We observed no spread of populations away from roads between the surveys in 2010 and 2011. Most of the landscapes were open with little ground cover (pine plantation), and the surveyors found that once they had a search image for A. stricta, plants could be seen from a substantial distance (not quantified here). In cases where plants did occur away from roads, there was circumstantial evidence that it was due to plantation activity (harvesting, clear felling or planting) or that plants were spreading along hiking trails. We found no substantial spread of populations along roads after one year. All plants found in the 2011 follow-up survey were within $100 \mathrm{~m}$ of plants recorded in 2010, with $82 \%$ of plants found within $20 \mathrm{~m}$ of previously recorded plants (Fig. 2c). There was also no apparent relationship found between the location of plants and their proximity to watercourses. Based on these observations, the resulting risk map (Fig. 2c) suggests that most intensive searching for new plants (i.e. walked surveys) should be done within $100 \mathrm{~m}$ of plants recorded previously (regardless of distance to road-edge) and within $30 \mathrm{~m}$ of road edges.

Management planning

\section{Risk assessment}

Based on data and observations gathered during this study and available literature, A. stricta would fail a pre-border risk assessment (Supplementary Material Appendix E; overall score was 18 , where $>6$ indicates 
potentially invasive) and should be considered a highrisk species in South Africa.

\section{Reproductive output}

The minimum height at which plants were found to reproduce was $\sim 30 \mathrm{~cm}$, while $67 \%$ of plants between 1 and $2 \mathrm{~m}$ showed signs of reproductive maturity (Fig. 3a). Reproductive output (estimated from flower bud counts) increased exponentially with plant height $\left(\mathrm{R}^{2}=0.788, \mathrm{~F}=125, p<0.0001\right.$; Fig. 3b). The largest tree measured in the population $(3.8 \mathrm{~m}$ tall) had $>12,000$ flower buds. Several plants found during the 2011 survey, in areas that were surveyed intensively in 2010, showed signs of developing flowers. Therefore, as it is unclear if reproduction begins after one or 2 years, annual surveys are warranted to prevent seed set.

\section{Seed banks and seed viability}

The seed bank size measured under the plant canopy was $\sim 1,000$ seeds $\mathrm{m}^{-2}$ (251 seeds $\pm 2.1 \mathrm{SD}$ per $0.25 \mathrm{~m}^{2}$ soil sample). The soil collected from the road grader also contained two seeds, showing that $A$. stricta seeds are, as expected, transported during road grading. Soil cores sampled from across-road transects showed that seeds had been deposited up to $6 \mathrm{~m}$ from the road, but that $79 \%$ of seeds were along road edges (i.e. along the regularly maintained roadside drainage ditches and ridges). Only $6 \%(2-11,95 \% \mathrm{CI})$ of the seeds sampled from the seed bank were viable.

\section{Regrowth from seed bank}

The re-survey of the study area in 2011 found $\sim 15,126$ plants (i.e. a $24 \%$ reduction from 2010) with a total invaded area of approximately 92 ha. Most of the plants found at sites were new seedlings of $<50 \mathrm{~cm}$ (Fig. 3c), with the incidence of resprouting low at all sites (56 plants in total). Field observations showed that resprouting only occurred if the initial cut was made above the lowest branch; correct cutting and herbicide stump application appears to be highly effective.

\section{Discussion}

Deciding whether to attempt eradication of introduced species or opt for containment is an important
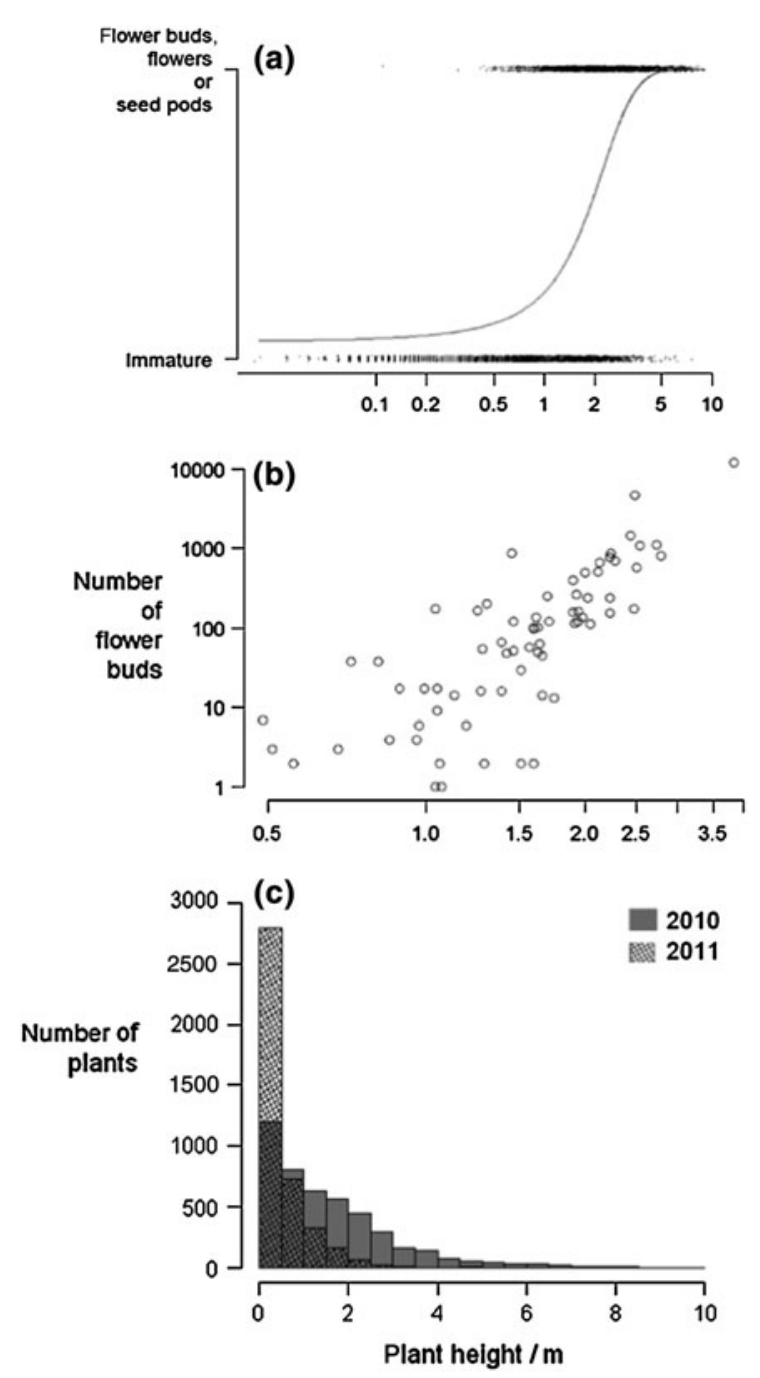

Fig. 3 a Plant height of Acacia stricta at reproductive maturity. The relationship shown is from a fitted generalised linear model with binomial errors using plant height as an explanatory variable to predict the presence of flowers, flower buds or seedpods; $\mathbf{b}$ the increase in reproductive output (estimated by the number of flower buds per plant) with plant height; $\mathbf{c}$ size histogram of A. stricta plants measured in 2010 and in the follow up survey in 2011

management question and an important focus in invasive species research (e.g. Hester et al. 2013). Uncertainty of invasion extent when attempting eradication can lead to failure if the invasion is poorly delimited and resources are insufficient to remove additional populations (Moore et al. 2011). Accurate delimitation is therefore a crucial component of assessing a species for eradication. We have 
demonstrated a multi-scale approach for improving detection and rapid delimitation of a species for which there is uncertainty in the total extent in order to assess management feasibility (Fig. 1).

A prerequisite of the framework presented here is some prior knowledge of where the species occurs. In the case of A. stricta, several records in the South African Plant Invaders Atlas, along with reports from landowners, provided a good basis for our survey. A strong targeted awareness campaign and a detailed initial search effort will improve the prediction accuracy, but the process can be on-going, i.e. model predictions are improved as more information becomes available. In this way, the search effort is adjusted as more information becomes available (i.e. if populations are found or if areas are searched but no plants are found).

\section{Predicting where to search}

The predictive mapping of A. stricta provides a means of prioritizing search efforts by minimizing the total area that requires searching, simultaneously increasing the probability of detecting an A. stricta population before it is able to grow in size and accumulate large seed banks. Implementing the search strategy within the study area will significantly reduce the overall costs and effort of surveying (by $83 \%$ or $\sim 12,000$ ZAR per year) and clearing costs would potentially be less if populations are detected at low density and before any significant seed banks are able to form.

The forestry industry is the most likely pathway of introduction of this species and given the current association of $A$. stricta with plantations in its known invasive range, targeted searches and awareness should be focussed particularly in climatically-suitable forestry areas (Fig. 2a). Possible over-estimation of climatic suitability in South Africa based on homerange distribution patterns (Rejmánek 2000) could over-estimate the number of plantations in the country suitable for A. stricta invasions. However as surveillance at a national-scale will predominantly be passive (i.e. creating awareness and gathering reports from local land users) this is unlikely to have any major cost implications and, as such, it would be better to have a more liberal species distribution model.

Active surveys at the landscape scale are very expensive, and ways of objectively prioritizing particular areas would improve the cost-effectiveness of management. The movement of A. stricta is most likely a result of soil seed bank spread by road maintenance vehicles such as road graders and plantation harvesting vehicles or equipment (Supplementary Material Appendix B). While this dispersal could be prevented by limiting vehicle activities in the area, the costs of operating road grading equipment greatly outweighs the costs of clearing A. stricta, making it expensive and impractical to establish quarantine sites for heavy-equipment working in invaded areas. Instead, increased monitoring at sites where plantation or road maintenance activity has occurred within the previous year should be incorporated into the management plans.

At a local scale, A. stricta seeds appear to occur mostly underneath canopies, and dispersal appears to be primarily via gravity or the movement of soil (e.g. there was no evidence of seed dispersal by ants). This is advantageous for management of this species; many other acacias have adaptations for dispersal by birds (Gibson et al. 2011) which would require a much greater search effort. Proximity to roads and previously recorded plant localities provide a good indication of where to search for plants at a local scale. However, we suspect that spread of plants away from roads can occur following disturbance and soil movement away from the roadside during planting, harvesting and clear-felling of plantation compartments.

One major concern in the modelling approach taken here is its correlative nature-resultant predictions of risk are largely a function of the stage of invasion (Peterson 2005). Acacia stricta, like most other eradication targets, is at a relatively early stage of invasion. As such, predicting areas at risk of invasion at localized spatial scales by A. stricta based on its current distribution might under-predict the total area where plants could potentially occur and where surveillance is required (Jimenez-Valverde et al. 2011; Rouget et al. 2004). Restricting surveillance to roadsides in plantations and limiting monitoring in natural areas might not detect spread to areas we are most interested in conserving. The risk maps of $A$. stricta should therefore not be considered as a predictor of potential long-term population expansion, but rather as a tool to guide the immediate systematic surveillance to be done on a regular basis. Occasional surveillance should perhaps be undertaken in areas 
where A. stricta is not predicted to occur as verification (Fox et al. 2009).

Variation in detection efficiency, mostly determined by the growth form of the target species and the structure of the surrounding vegetation, could influence both the model predictions and the decision outcome (Christy et al. 2010; Reese et al. 2005). Although not quantified in this study, we expect that the detection probability of $A$. stricta is high given its very conspicuous growth form (even when not in flower) compared to the surrounding vegetation and that searching was done during flowering season to improve detectability. Low detection rates could underestimate the extent of the species' extent and result in a failed eradication attempt. In systems where detection probability is low, greater search effort will need to be invested particularly in areas where species are predicted more likely to occur (Hauser and McCarthy 2009). But arguably the most effective strategy to increase detection will be to keep reminding land managers in the area to look out for the species through targeted awareness.

Passive surveillance (i.e. sightings and reports from managers and field workers) have proved to be an important part of locating and delimiting $A$. stricta invasions. All populations found in the initial surveys were identified by land managers, and all subsequent populations found to date were reported by local conservation or plantation managers and field workers in the Knysna area in response to the increased awareness of $A$. stricta. This highlights the benefit of awareness campaigns and active involvement in eradication projects for locating new populations. At a national level, passive surveillance (enabled through awareness campaigns) would be the most cost-effective approach to detecting new populations.

Considering this role of passive surveillance in the detection of A. stricta, a highly visible, distinctive species found in well-travelled areas, it is questionable whether a risk mapping approach at the landscape scale is necessary for this species. In the case of $A$. stricta, ensuring stakeholder buy-in and collaborating with people on the ground that have good local knowledge of invasive species would probably be a reliable way of finding new populations, whereas a risk mapping approach would be more useful at a local scale where effective control requires finding every individual.
Eradication feasibility

Given that the invasion by A. stricta has been detected at a relatively early stage, and we have so far provided strategies for effective surveillance and awareness, we consider A. stricta to be a good candidate for eradication (i.e. category 1a under South Africa's proposed invasive species regulations as part of the National Environmental Management: Biodiversity Act 10 of 2004) at its present extent if immediate action is taken to control populations and reduce spread. A focused co-ordinated management plan needs to be implemented to provide effective strategies for finding and removing all populations of $A$. stricta and preventing further seed production and spread, but such a scheme need not be substantially more expensive than current invasive species management (Wilson et al. 2013). Following discussions with stakeholders, it was agreed that a collaborative effort involving all relevant land managers and coordinated by SANBI's Invasive Species Programme would be the best way to manage A. stricta. A longterm management plan that involves annual targeted vehicle searches and removal of plants at all sites was agreed upon by all parties.

Age at reproduction, reproductive output and seed bank size and longevity will influence the frequency of management and the timeframe of an eradication programme. Since A. stricta can possibly reach reproductive maturity within one year, follow-up clearing should be done on an annual basis to prevent plants contributing to the seed bank. With the current distribution (in 2011) of approximately 92 ha and an estimated cost of clearing of 400 ZAR per ha (based on costs of clearing alien plants collated by MTO Forestry Pty Ltd.), the estimated cost of removing all plants at existing sites is $\sim 36,800$ ZAR per year. Further studies are needed to determine the depletion rates of the seed bank in order to estimate the likely duration and the total cost of the eradication programme.

The feasibility of eradication of A. stricta will need to be re-evaluated if additional populations are found elsewhere in South Africa. However it seems unlikely that this species has gone unnoticed in other parts of the country given the distinctive erect growth habit and inflorescence position that easily distinguish adult plants from other acacias, and the general interest and attention paid to invasive Australian acacias in South 
Africa. However, if eradication was found to be unfeasible a modelling approach similar to that demonstrated here could be used to improve containment efforts or used as a tool to prioritize invasive species management in areas with important ecological assets or threatened habitats.

\section{Conclusions}

Risk mapping provides a useful method of consolidating information in a form that can produce informative management products. Mapping and assessing invasions at multiple scales is important for accurate delimitation and assessment of eradication feasibility. However, the likely lack of generality of risk mapping means that a specific risk map would be required for each species. While risk maps can reduce the overall costs and effort required for searching and monitoring, our experience has shown that active involvement of stakeholders in the surveillance plays an important role in the rapid delimitation of a species' invasion extent.

Acknowledgments This project was funded by the DST-NRF Centre of Excellence in Invasion Biology and the Working for Water (WfW) Programme through their collaborative project on "Research for Integrated Management of Invasive Alien Species" and through the WfW funded South African National Biodiversity Institute's Invasive Species Progamme. DMR acknowledges financial support from the National Research Foundation (Grant 85417), and the Oppenheimer Memorial Trust. We thank Dane Paijmans and Suzaan Kritzinger-Klopper for assistance in the field; Ernita van Wyk for co-ordinating the management meeting; and SANParks and MTO Forestry (Pty) Ltd. for logistical support.

\section{References}

Butcher ER, Kelly D (2011) Physical and anthropogenic factors predict distribution of the invasive weed Tradescantia fluminensis. Austral Ecol 36:621-627

Cacho OJ, Spring D, Pheloung P et al (2006) Evaluating the feasibility of eradicating an invasion. Biol Invasions 8:903-917

Cacho OJ, Hester S, Spring D (2007) Applying search theory to determine the feasibility of eradicating an invasive population in natural environments. Aust J Agric Resourc Econ 51:425-443

Cacho OJ, Spring D, Hester S et al (2010) Allocating surveillance effort in the management of invasive species: a spatially-explicit model. Environ Model Softw 25:444-454
Christy MT, Yackel Adams AA, Rodda GH et al (2010) Modelling detection probabilities to evaluate management and control tools for an invasive species. J Appl Ecol 47:106-113

Ferguson L, Duncan CL, Snodgrass K (2003) Backcountry road maintenance and weed management. USDA Forest Service Technology and Development Program Missoula, USA

Fox JC, Buckley YM, Panetta FD et al (2009) Surveillance protocols for management of invasive plants: modelling Chilean needle grass (Nassella neesiana) in Australia. Divers Distrib 15:577-589

Gaertner M, den Breeyen A, Cang H et al (2009) Impacts of alien plant invasions on species richness in Mediterraneantype ecosystems: a meta-analysis. Prog Phys Geogr 33:319-338

Gardener MR, Atkinson R, Rentería JL (2010) Eradications and people: lessons from the plant eradication program in Galapagos. Restor Ecol 18:20-29

Gelbard JL, Belnap J (2003) Roads as conduits for exotic plant invasions in a semiarid landscape. Conserv Biol 17:420-432

Gibson M, Richardson DM, Marchante E et al (2011) Reproductive ecology of Australian acacias: fundamental mediator of invasive success? Divers Distrib 17:911-933

Giorgis MA, Tecco PA, Cingolani AM et al (2011) Factors associated with woody alien species distribution in a newly invaded mountain system of central Argentina. Biol Invasions 13:1423-1434

Glen HF (2002) Cultivated plants of Southern Africa. South African National Biodversity Institute and Jacana, Johannesburg

Gordon DR, Riddle B, Pheloung PC et al (2010) Guidance for addressing the Australian weed risk assessment questions. Plant Prot Q 25:56-74

Harrison S, Hohn C, Ratay S (2002) Distribution of exotic plants along roads in a peninsular nature reserve. Biol Invasions $4: 425-430$

Hauser CE, McCarthy MA (2009) Streamlining 'search and destroy': cost-effective surveillance for invasive species management. Ecol Lett 12:683-692

Henderson L (1998) Southern African plant invaders atlas (SAPIA). Appl Plant Sci 12:31-32

Hester SM, Cacho OJ, Panetta FD et al (2013) Economic aspects of post-border weed risk management. Divers Distrib 19:580-589

Hijmans RJ, Cameron SE, Parra JL et al (2005) Very high resolution interpolated climate surfaces for global land areas. Int J Climatol 25:1965-1978

Jimenez-Valverde A, Peterson AT, Soberon J et al (2011) Use of niche models in invasive species risk assessments. Biol Invasions 13:2785-2797

Kaplan H, van Zyl HWF, Le Roux JJ et al (2012) Distribution and management of Acacia implexa (Benth.) in South Africa: a suitable target for eradication? S Afr J Bot $83: 23-35$

Kery M, Gregg KB (2003) Effects of life-state on detectability in a demographic study of the terrestrial orchid Cleistes bifaria. J Ecol 91:265-273

Le Maitre DC, Sheppard AW, Marchante E et al (2011) Impacts of Australian Acacia species on ecosystem services and functions, and options for restoration. Divers Distrib 17:1015-1029 
Loiselle BA, Jørgensen PM, Consiglio T et al (2008) Predicting species distributions from herbarium collections: does climate bias in collection sampling influence model outcomes? J Biogeogr 35:105-116

Moore JL, Runge MC, Webber BL et al (2011) Attempt to contain or eradicate? Optimising the management of Australian acacia invasions in the face of uncertainty. Divers Distrib 17:1047-1059

Mortensen DA, Rauschert ESJ, Nord AN et al (2009) Forest roads facilitate the spread of invasive plants. Invasive Plant Sci Manag 2:191-199

Myers JH, Simberloff D, Kuris AM et al (2000) Eradication revisited: dealing with exotic species. Trend Ecol Evol 15:316-320

Panetta FD (2009) Weed eradication-an economic perspective. Invasive Plant Sci Manag 2:360-368

Panetta FD, Lawes R (2005) Evaluation of weed eradication programs: the delimitation of extent. Divers Distrib 11:435-442

Peltzer DA, Ferriss S, FitzJohn RG (2008) Predicting weed distribution at the landscape scale: using naturalized Brassica as a model system. J Appl Ecol 45:467-475

Peters J (2005) Tetrazolium testing handbook, contribution No. 29 to the handbook on seed testing. Association of Official Seed Analysts, Las Cruces, USA

Peterson AT (2005) Predicting potential geographic distributions of invading species. Curr Sci 89:9

Pheloung PC, Williams PA, Halloy SR (1999) A weed risk assessment model for use as a biosecurity tool evaluating plant introductions. J Environ Manage 57:239-251

Phillips SJ, Anderson RP, Schapire RE (2006) Maximum entropy modeling of species geographic distributions. Ecol Model 190:231-259

Poynton RJ (2009) Tree planting in Southern Africa. Department of Agriculture, Forestry and Fisheries, Pretoria

Pyšek P, Richardson DM (2010) Invasive species, environmental change and management, and health. Ann Rev Environ Resourc 35:25-55

Reese GC, Wilson KR, Hoeting JA et al (2005) Factors affecting species distribution predictions: a simulation modelling experiment. Ecol Appl 15:554-564

Rejmánek M (2000) Invasive plants: approaches and predictions. Austral Ecol 25:497-506

Rejmánek M, Pitcairn MJ (2002) When is eradication of exotic pest plants a realistic goal? In: Veitch CR, Clout MN (eds) Turning the tide: the eradication of invasive species. IUCN Invasive Species Specialist Group, Gland, pp 249-253
Richardson DM, Kluge RL (2008) Seed banks of invasive Australian Acacia species in South Africa: role in invasiveness and options for management. Perspect Plant Ecol Evol Syst 10:161-177

Richardson DM, Carruthers J, Hui C et al (2011) Humanmediated introductions of Australian acacias - a global experiment in biogeography. Divers Distrib 17:771-787

Rouget M, Richardson DM, Nel JL et al (2004) Mapping the potential ranges of major plant invaders in South Africa, Lesotho and Swaziland using climatic suitability. Divers Distrib 10:475-484

Simberloff D (2003a) Eradication: preventing invasions at the outset. Weed Sci 51:247-253

Simberloff D (2003b) How much information on population biology is needed to manage introduced species? Conserv Biol 17:83-92

Spooner PG, Lunta ID, Briggs SV et al (2004) Effects of soil disturbance from roadworks on roadside shrubs in a fragmented agricultural landscape. Biol Conserv 117:393-406

Taylor K, Brummer T, Taper ML et al (2012) Human-mediated long-distance dispersal: an empirical evaluation of seed dispersal by vehicles. Divers Distrib 18:942-951

Thompson GD, Robertson MP, Webber BL et al (2011) Predicting the sub-specific identity of invasive species using distribution models: Acacia saligna as an example. Divers Distrib 17:1001-1014

van Wilgen BW, Dyer C, Hoffmann JH et al (2011) Nationalscale strategic approaches for managing introduced plants: Insights from Australian acacias in South Africa. Divers Distrib 17:1060-1075

Vanderhoof M, Holzman BA, Rogers C (2009) Predicting the distribution of perennial pepperweed (Lepidium latifolium), San Francisco Bay area, California. Invasive Plant Sci Manag 2:260-269

Wilson JRU, Gairifo C, Gibson MR et al (2011) Risk assessment, eradication, containment, and biological control: global efforts to manage Australian acacias before they become widespread invaders. Divers Distrib 17:1030-1046

Wilson JRU, Ivey P, Manyama P et al (2013) A new national unit for invasive species detection, assessment and eradication planning. S Afr J Sci 109:13. doi:10.1590/sajs.2013/ 20120111

Zenni RD, Wilson JRU, Le Roux JJ et al (2009) Evaluating the invasiveness of Acacia paradoxa in South Africa. S Afr J Bot 75:485-496 


\section{APPENDIX A}

\section{Information flyer}

In order to get further reports of Acacia stricta populations, information flyers were distributed by hand to local land managers. Managers were then asked for the locations of populations of this species if they had encountered any. The flyers were targeted at groups who routinely work in the field and were therefore likely to recognise $A$. stricta populations. These included conservation organisations (South African National Parks and CapeNature) and plantation managers at forestry companies (MTO Forestry (Pty) Ltd. and PG Bison), as well as a local tree nursery. The flyers contain a detailed description of $A$. stricta including its distinguishing features. Reports are directed to the South African National Biodiversity Institute's Invasive Species Programme for follow up to determine whether they are accurate and whether they are indeed new populations or have been previously recorded.
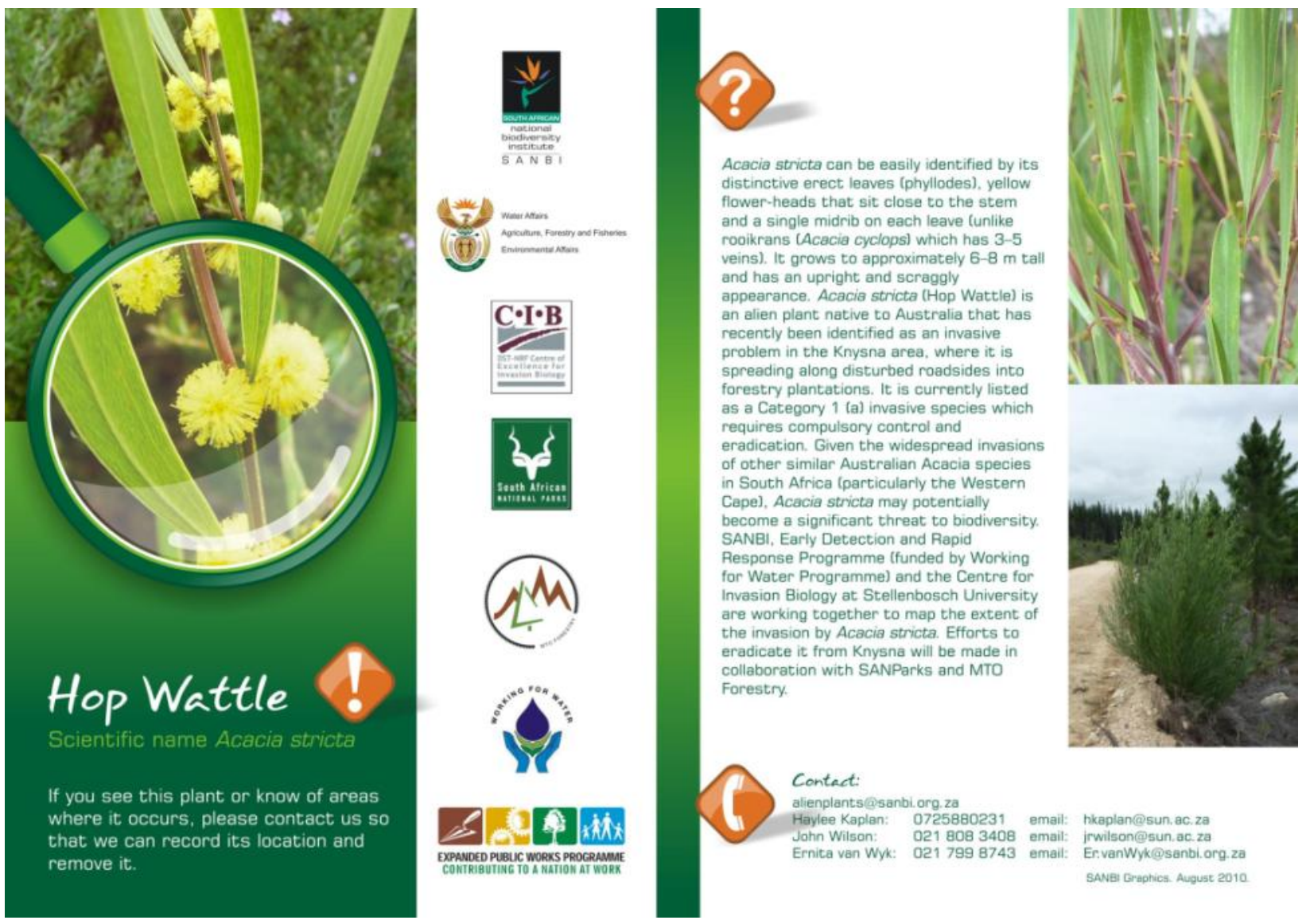

Acacia stricta can be easily identified by its distinctive erect leaves (phyllodes), yellow flower-heads that sit close to the stem and a single midrib on each leave (unlike rooikrans (Acacia cyclops) which has 3-5 veins). It grows to approximately $6-8 \mathrm{~m}$ tal and has an upright and scraggly

appearance. Acacia stricta (Hop Wattie) is an alien plant native to Australia that has premem in the Knysna area, problem in the Knysna area, where it is spreading along disturbed roadsides into forestry plantations. It is currently listed as a Category 1 (a) invasive species which requires compulsory control and eradication. Given the widespread invasion of other similar Australian Acacia species in South Africa (particularly the Western Cape], Acacia stricta may potentially become a significant threat to biodiversity. SANBI, Early Detection and Rapid RANBI, Early Detection and Rapid Response Programme (funded by Workin for Water Programmel and the Centre for Invasion Biology at Stellenbosch University are working together to map the extent of the invasion by Acacia stricta. Efforts to eradicate it from Knysna will be made in collaboration with SANParks and MTO Forestry.

If you see this plant or know of areas

where it occurs, please contact us so that we can record its location and

Contact:

alienplants@sanbi. org. 2

Haylee Kaplan: 0725880231 email: hkaplan@sun.ac.za John Wilson: 0218083408 email: jrwilson@sun.ac.za Ernita van Wyk: 0217998743 email: Er.vanWyk@sanbi.org.za SANeI Graphics. August 2010 


\section{APPENDIX B}

\section{Video of road grading equipment moving seeds of Acacia stricta}

The video available at

http://academic.sun.ac.za/cib/supplementary/Kaplat\%20et\%20al\%202014\%20Biological\%20Invasions\% 20Supplementary\%20Material\%20Appendix\%20B.AVI

shows a road grader cutting a drainage ditch into the side of a dirt road used by plantation vehicles as part of routine road maintenance. The ditch was in an area infested by Acacia stricta (the light green erect saplings visible in the mid-ground of the picture). The soil attached to the blade of the grader was sampled after the video was taken, and seeds of Acacia stricta were found in this soil, indicating that the road grader is a method for seed dispersal. 


\section{APPENDIX C}

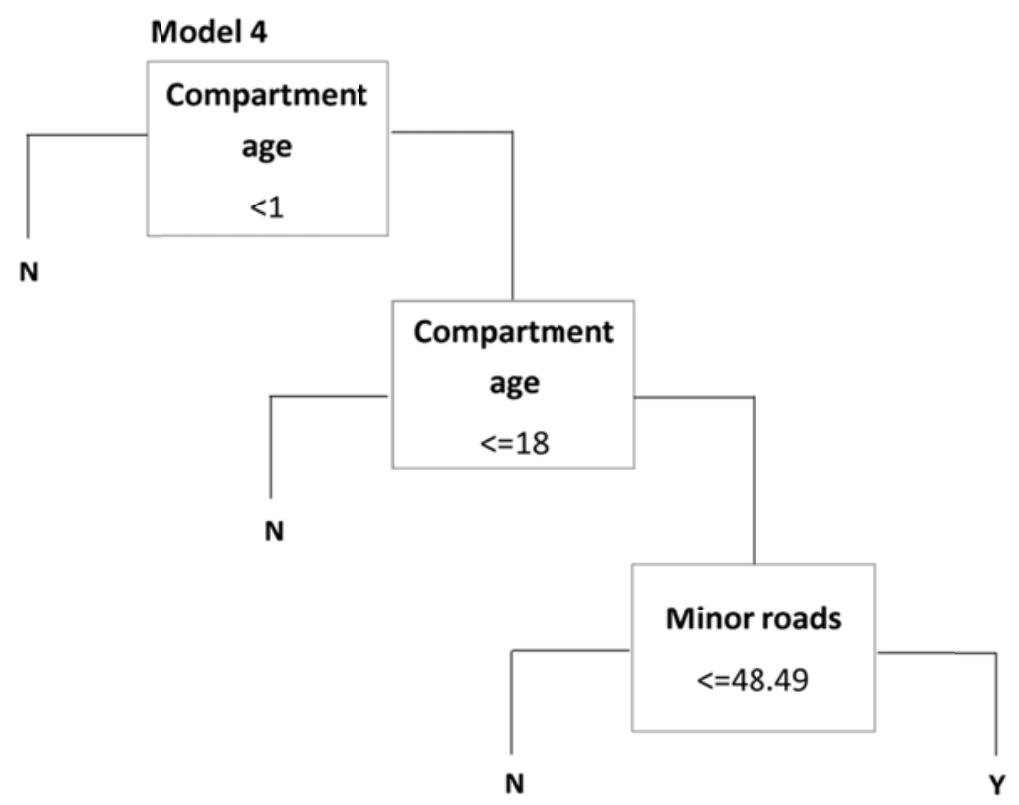

Appendix C: Recursive partitioning model used to predict the occurrence of Acacia stricta based on age of plantation compartment and distance to minor roads. Presence and absence data used in this model were restricted to within $50 \mathrm{~m}$ of roads. 


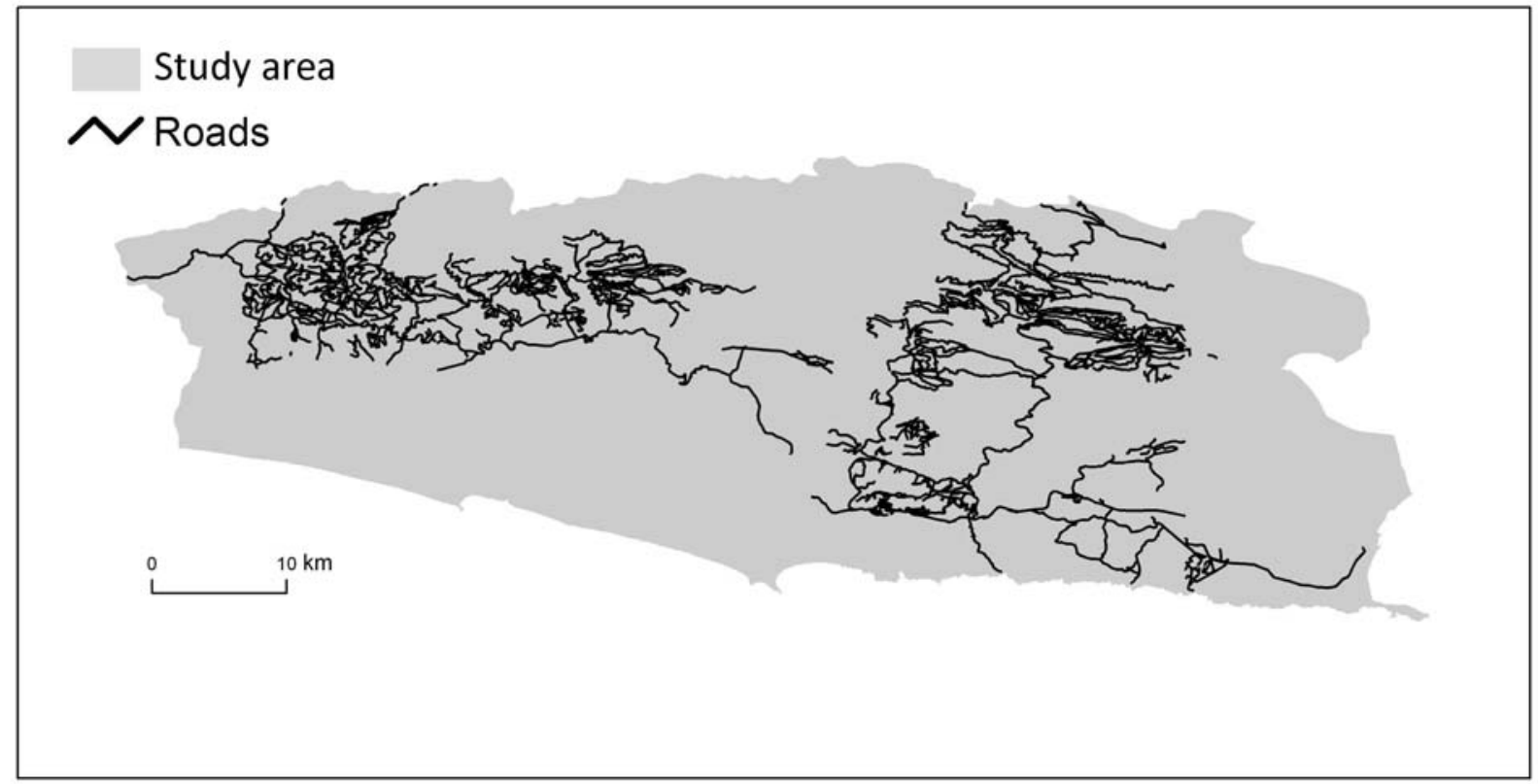

Appendix D: Required route for vehicular surveys to search all areas predicted as being at risk of invasion by Acacia stricta. 
APPENDIX E: Data for Acacia stricta for the Australian Weed Risk Assessment Protocol (following Pheloung et al 1999)

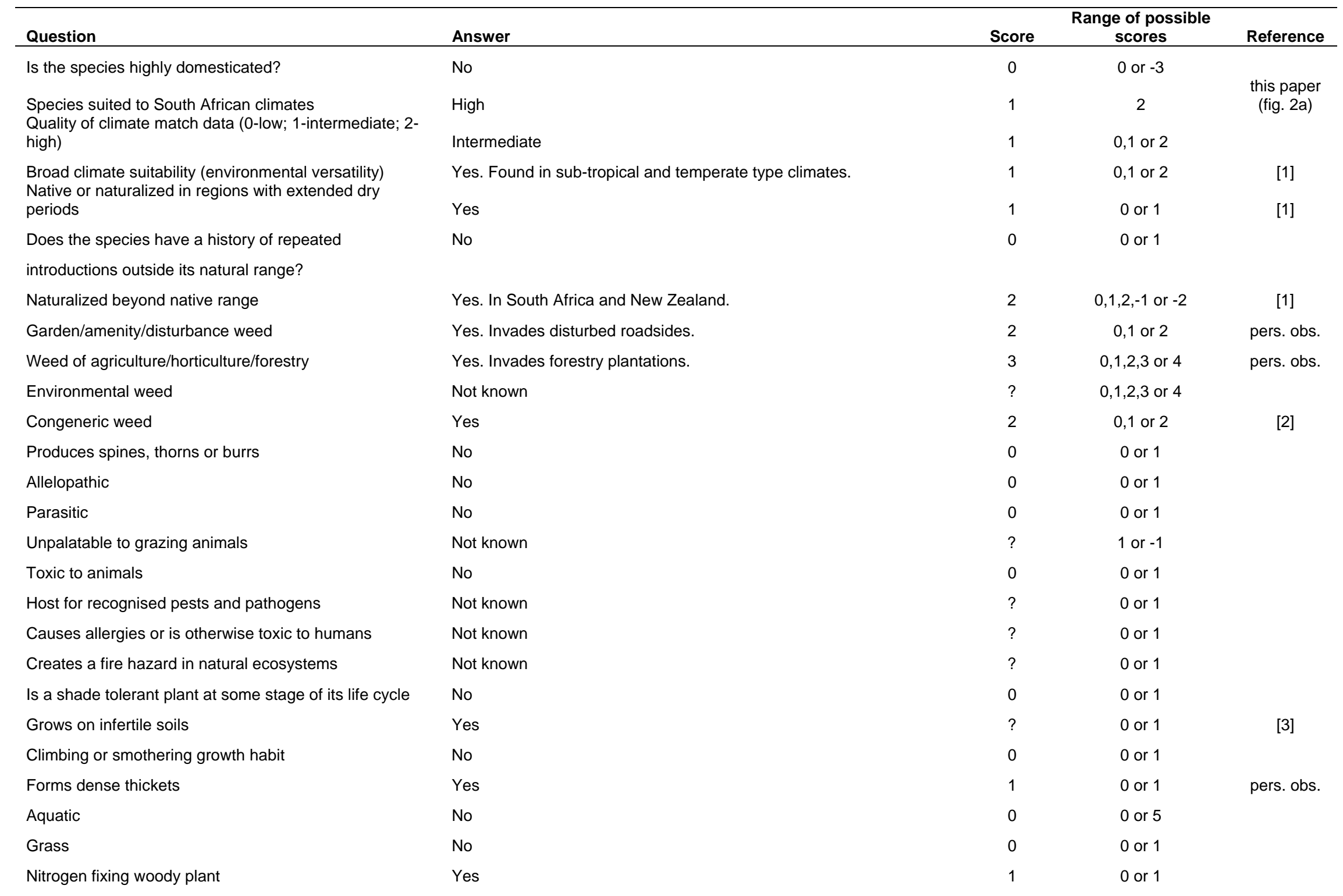




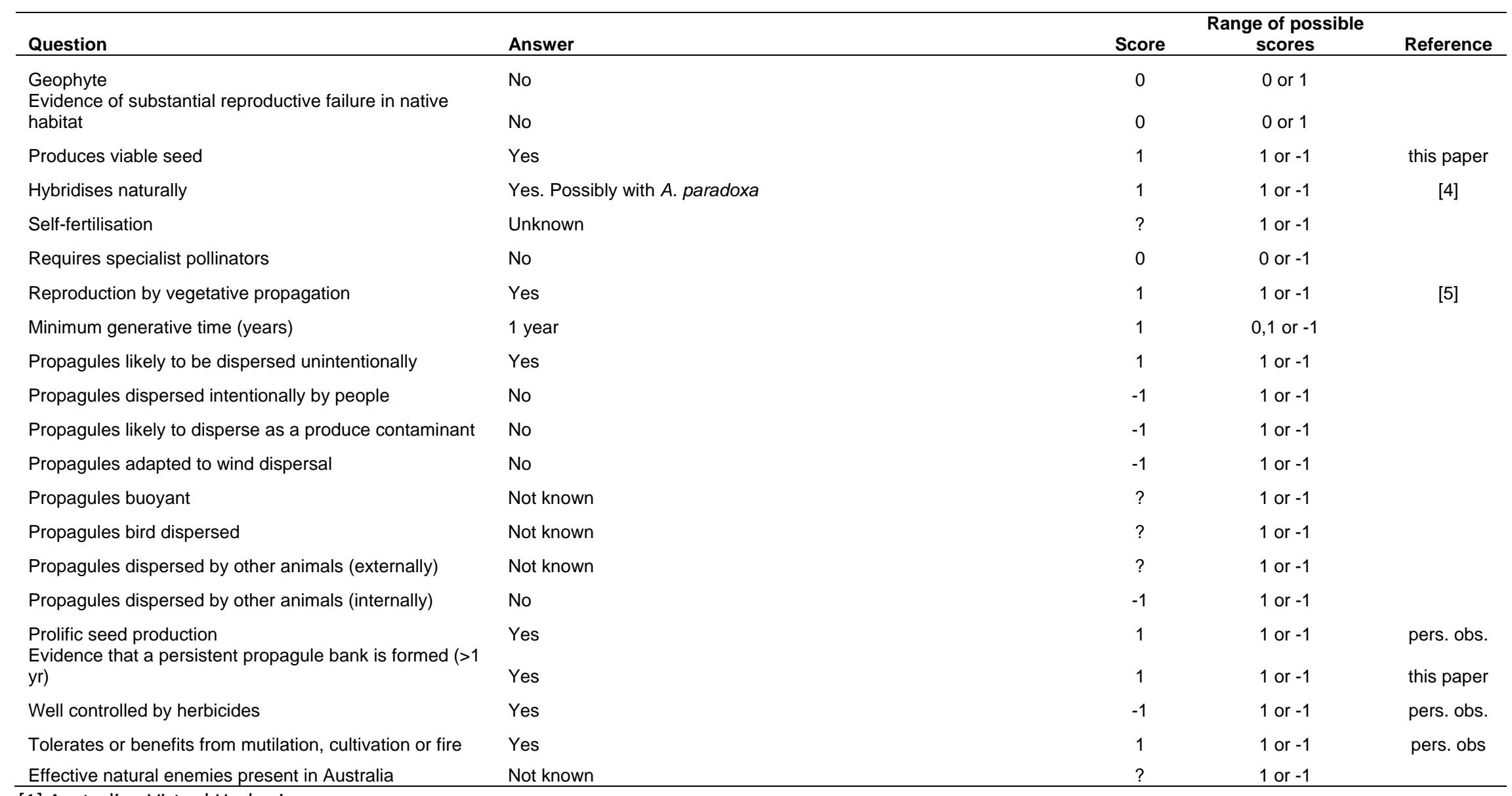

\section{[1] Australian Virtual Herbarium}

[2] Le Maitre, D. C., Gaertner, M., Marchante, E., Ens, E. J., Holmes, P. M., Pauchard, A., O'Farrell, P. J., Rogers, A. M., Blanchard, R., Blignaut, J. \& Richardson, D.

M. (2011) Impacts of invasive Australian acacias: implications for management and restoration. Diversity and Distributions, 17, 1015-1029

[3] www.intertwine.com.au

[4] Maslin, B. R. (2001) Wattle. Acacias of Australia. CSIRO Publishing \& ABRS, Perth.

[5] http://www.yarraranges.vic.gov.au

Pheloung, P. C., Williams, P. A. \& Halloy, S. R. (1999) A weed risk assessment model for use as a biosecurity tool evaluating plant introductions. Journal of Environmental Management, 57, 239-251. 